\title{
Transcatheter closure of secundum atrial septal defect in adults: report of our first experience in a developing country
}

This article was published in the following Dove Press journal:

Open Access Surgery

16 April 2014

Number of times this article has been viewed

B Adeola Animasahun'

Yele Aluko²

Adeyemi Johnson ${ }^{3}$

Kofo Ogunyankin ${ }^{3}$

Sunita Maheshwari ${ }^{4}$

'Department of Paediatrics and Child Health, Lagos State University College of Medicine, Lagos, Nigeria; ${ }^{2}$ Mid

Carolina Cardiology, Charlotte, NC, USA; ${ }^{3}$ First Cardiology Consultants, Lagos, Nigeria; ${ }^{4}$ Narayana Hrudayalaya Institute of Cardiac Sciences, Bangalore, India
Correspondence: B Adeola Animasahun Department of Paediatrics and Child Health, Lagos State University College of Medicine, I-5 Oba Akinjobi Road, Ikeja, Lagos Nigeria

$\mathrm{Tel}+234$ I 8037250264

Email deoladebo@yahoo.com
Background: Since the first report on device closure of atrial septal defect (ASD) in 1976, the procedure has gained wide acceptance and has been used worldwide, including parts of Africa. The advantages when compared to surgical closure include a shorter procedure time and hospital stay and no scarring. This mode of treatment was not available in Nigeria prior to the cases reported here, requiring patients to travel abroad for the procedure.

Methods: A cardiac catheterization laboratory became available in Lagos, Nigeria in 2009, and in December 2010 the laboratory collaborated with Lagos State University College of Medicine and Lagos State University Teaching Hospital to perform the device closure on two women (aged 34 and 62 years) with secundum ASD. To the best of our knowledge, these are the first times the procedure has been performed in Nigeria.

Results: Both patients made successful recovery and are stable.

Conclusion: Transcatheter closure of ASD is now safe and available in Nigeria.

Keywords: atrial septal defect, transcatheter closure, Nigeria

\section{Introduction}

Atrial septal defect (ASD) is one of the more commonly recognized congenital cardiac anomalies presenting in adulthood. It is characterized by a defect in the interatrial septum, allowing pulmonary venous return to pass directly from the left atrium (LA) to the right atrium (RA). ${ }^{1}$ Cardiac sequelae depends on the size of the shunt and associated anomalies, which can range from no sequelae to right sided volume overload, pulmonary artery hypertension, and atrial arrhythmias. ${ }^{2}$

The traditional method of closure has been surgical, which has been practiced for more than 50 years, with expectations now reaching zero mortality. ${ }^{1}$ Recently, the development of catheter-based technology has made device closure the first option for closure of ostium secundum ASD. ${ }^{1}$ The first report on device closure of ASD was in 1976 by King et al. ${ }^{3}$ It has the advantage of saving the patient from open heart surgery and cardiopulmonary bypass and allowing a shorter hospital stay and faster rehabilitation. ${ }^{4}$

This mode of therapy has gained wide acceptance worldwide and is routine in many countries including some centers in Africa, but before the cases presented here, it had never been performed in Nigeria. In October 2009, a private cardiac catheterization laboratory was opened in Lagos at the Reddington Multispecialty Hospital. The catheter laboratory had been in use since July 2009 for coronary angiography, diagnostic cardiac catheterization for pediatric and adult patients with structural heart disease, successful percutaneous closure of patent ductus arteriosus, and balloon valvuloplasty 
had also been carried out in the laboratory. In December 2010, a successful transcatheter device closure was performed on a 34-year-old woman with ostium secundum ASD and later in a 62-year-old woman. The cases are thus presented to create awareness that the facility is now available in the region, as there are many children and adults suffering from this cardiac defect who could benefit from the procedure without having to travel abroad. This article is also expected to offer insight and initiate a thorough discussion addressing the priorities for establishing congenital cardiac care in developing countries.

\section{Case reports Case I}

A 34-year-old woman presented with fainting spells over a 1 month duration. She had gestational diabetes 5 years before presentation but was not a known hypertensive. She had been admitted to the intensive care unit of another hospital 4 months before presentation to our clinic due to a similar complaint, where she was diagnosed as having atrial fibrillation. She was married with three children, and she was taking the medications carvedilol, amiodarone, losartan, and metformin. Examination revealed an obese woman with oxygen saturation $\left(\mathrm{SpO}_{2}\right)$ in room air of $89 \%$, regular pulse rate of 54 beats per minute, blood pressure of $118 / 83 \mathrm{mmHg}$, with a grade $3 / 6$ ejection systolic murmur, maximal at the left upper sternal border. An initial assessment of bradycardia with pulmonary hypertension secondary to multiple pulmonary emboli was made.

Chest X-ray showed situs solitus, levocardia, cardiomegaly (cardiothoracic ratio $=0.65$ ), right atrial enlargement, and right ventricular enlargement with pulmonary plethora. Electrocardiogram showed features suggestive of right atrial enlargement and right ventricular hypertrophy. Transesophageal echocardiography (TEE) showed dilated RA and right ventricle (RV), moderate tricuspid regurgitation, pulmonary artery systolic pressure of $35 \mathrm{mmHg}, 34 \mathrm{~mm}$ ostium secundum ASD, with adequate rims, but an oscillatory mass around the lower end of the ASD, reduced left ventricular ejection fraction but free left atrial appendage. The patient was started on anticoagulants (enoxaparin and warfarin), with international normalized ratio monitoring. Three months later $\mathrm{SpO}_{2}$ had improved to $94 \%$ and a repeat TEE showed that the oscillatory mass at the lower end of ASD had cleared.

Femoral access was obtained. Coronary angiography revealed normal epicardial coronary arteries, and cardiac catheterization revealed a ratio of volume of pulmonary flow to systemic flow of $3: 1$, pulmonary vascular resistance of 5 wood units, significant step up of oxygen saturation in mid RA, and moderate pulmonary hypertension. After a right heart pressure assessment, a six French multipurpose catheter with an A-2 curve was passed to the superior vena cava. The catheter was then withdrawn slowly, aiming the tip toward the patient's left shoulder, until it passed through the ASD. The catheter was then advanced into the LA. After passing through the defect, the catheter was manipulated to the left upper pulmonary vein, and a stiff exchange-length guide wire was advanced to the pulmonary vein. The catheter was withdrawn, and balloon sizing of the defect was performed, which determined the size of the ASD as $36 \mathrm{~mm}$. A long sheath was advanced over the wire to the LA and carefully debubbled. The closure device (38 mm Amplatzer device) was folded into the sheath and advanced to the end of the sheath. The left atrial occluder was opened and pulled back firmly against the septum under echocardiography and angiography guidance. When the device was firm against the septum, the right atrial occluder was opened. When the position was appropriate as determined by angiography and echocardiography, the device was released. TEE showed the device in situ with no leakages. The patient made an uneventful postprocedure recovery; her $\mathrm{SpO}_{2}$ in room air improved to $98 \%$, and she was discharged home.

\section{Case 2}

A 62-year-old woman presented with effort intolerance, orthopnea, paroxysmal nocturnal dyspnea, dry cough, and palpitation of 5 months duration. Not a known hypertensive nor diabetic, examination revealed an asthenic, elderly woman with weight of $48 \mathrm{~kg}, \mathrm{SpO}_{2}$ in room air of $94 \%$, regular pulse rate of 93 beats per minute, blood pressure of 140/86 $\mathrm{mmHg}$, body mass index of $19.5 \mathrm{~kg} / \mathrm{m}^{2}$, with normal S1 but widely split fixed S2, grade 3/6 pansystolic murmur, maximal at the left lower sternal border and apex, and loud P2. An initial assessment of congestive cardiac failure with pulmonary hypertension secondary to a secundum ASD was made.

Chest X-ray showed situs solitus, levocardia, cardiomegaly (cardiothoracic ratio $=0.7$ ), right atrial enlargement, and right ventricular enlargement with pulmonary plethora. Electrocardiogram showed sinus rhythm with a rightward axis deviation, dominant $\mathrm{R}$ in V1, and $\mathrm{T}$ wave inversion in V1-V3, III, and $\mathrm{aVF}$, which are all suggestive of right ventricular enlargement, while transthoracic echocardiography (Figure 1) showed markedly dilated RA and RV with a large ostium secundum ASD, severe tricuspid regurgitation, moderate mitral regurgitation, and a left ventricular ejection fraction 


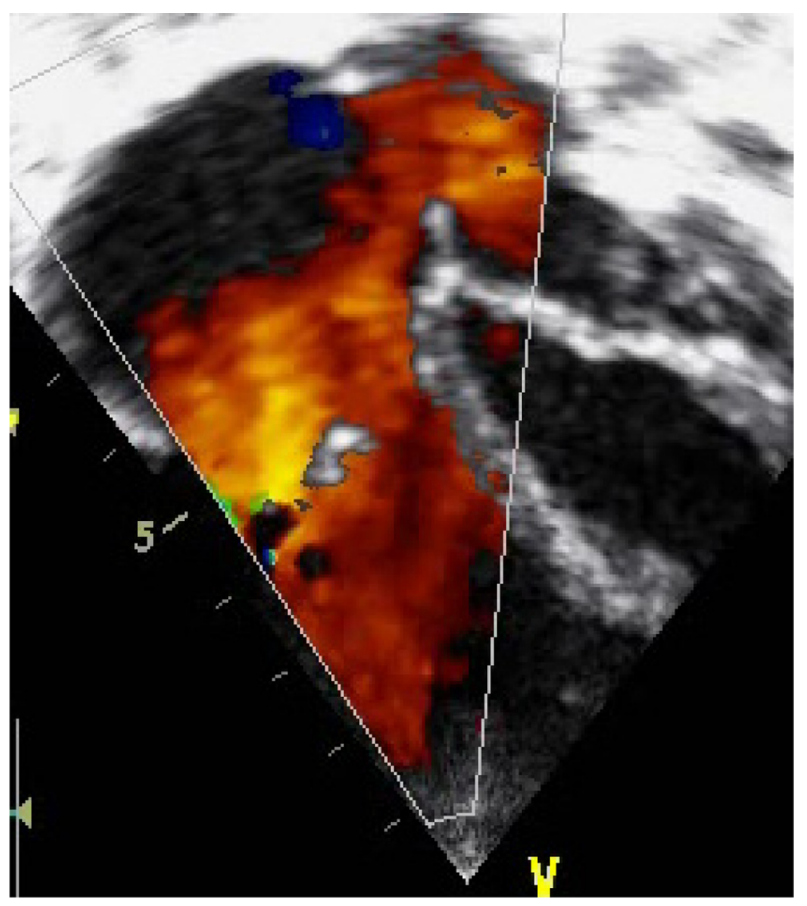

Figure I Apical four chamber view showing ostium secundum atrial septal defect (case 2).

of $60 \%$. TEE also confirmed a $28 \mathrm{~mm}$ secundum ASD with predominant left to right shunting, adequate rims, enlarged and globally hypokinetic RV, with right ventricular systolic pressure of $75 \mathrm{mmHg}$, moderate pulmonary hypertension, moderate tricuspid and mitral regurgitation. Left ventricular systolic function was normal as were her lipid profile and electrolyte and urea levels. Cardiac catheterization for coronary angiography revealed normal epicardial coronary arteries, and cardiac catheterization showed mean right atrial pressure of $5 \mathrm{mmHg}$, right ventricular pressure of $65 / 4 \mathrm{mmHg}$, pulmonary artery pressure of $65 / 18 \mathrm{mmHg}$, pulmonary flow to systemic flow ratio of 2.73:1, pulmonary vascular resistance of 6 wood units, significant step up of $\mathrm{SpO}_{2}$ in mid $\mathrm{RA}$, and moderate pulmonary hypertension. She also underwent a successful device closure of ASD using the same procedure described for Case 1, but the Amplatzer ASD device size was $32 \mathrm{~mm}$. When the position was appropriate as determined by angiography and echocardiography, the device was released and a follow-up echocardiography showed the device in situ with no leakage (Figures 2 and 3).

Both patients were treated with intravenous antibiotics (third generation cephalosporin) before femoral access. They continued with oral antibiotics (cephalosporin) for a total of 1 week after the procedure. Both patients stayed in hospital for 48 hours after the procedure for observation. Transthoracic echocardiographies were performed prior to discharge and were normal. The patients were started on low-dose

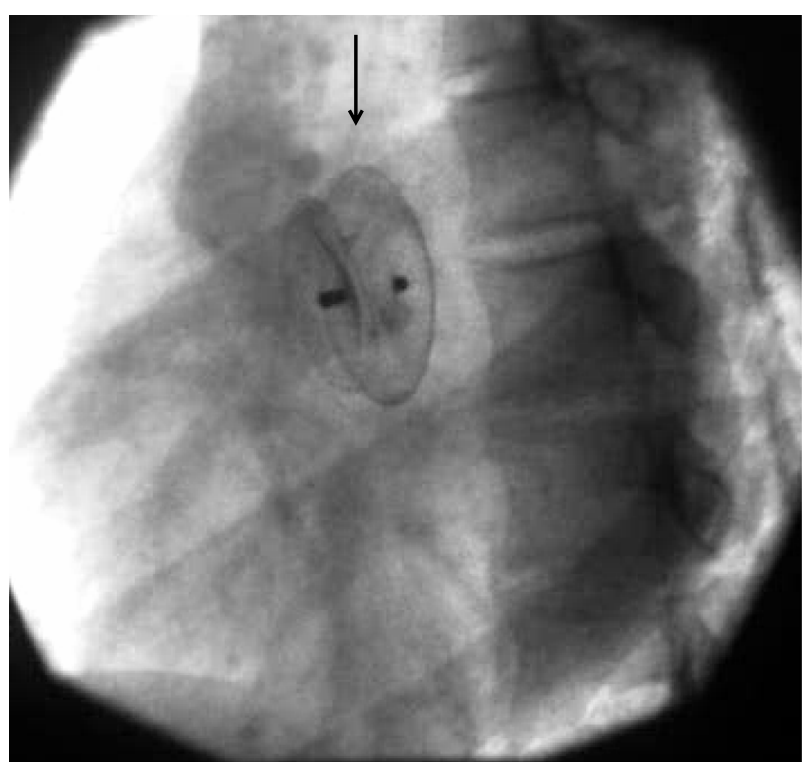

Figure 2 Arrow indicating atrial septal defect device in situ by fluoroscopy (case 2).

aspirin and clopidogrel for 6 months after the procedure. They have remained symptom free and stable on follow-up.

\section{Discussion}

The incidence of isolated ASD has been estimated at 1:1,500 live births, which is about $6 \%$ to $10 \%$ of all varieties of congenital heart disease. ${ }^{5,6}$ In Nigeria, the clinical and necropsy study by Antia $^{7}$ of 260 cases of congenital heart disease documented an incidence of $14.2 \%$ for ASD, while Okoromah et al, ${ }^{8}$ about 34 years later, documented an incidence of $20.2 \%$.

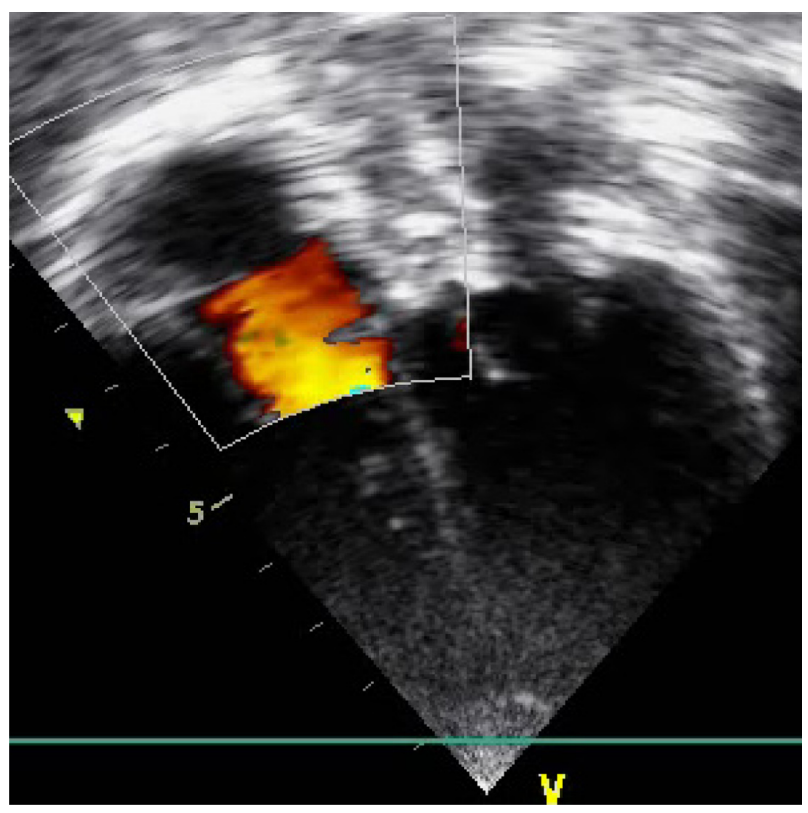

Figure 3 Postprocedure echocardiography showing atrial septal defect device in situ with no leakage (case I). 
Surgical closure of ASD has been practiced for well over 50 years, reaching the current expectation of zero mortality and an optimal functional result. ${ }^{1}$ In the attempt to minimize operative morbidity, practice has moved to a less invasive surgical approach, including minimal skin incisions, reduced opening of the thoracic cage, and alternative vascular access sites. More recently the development of catheter-based technology has advanced device occlusion as the first option for the closure of ostium secundum ASDs. ${ }^{1}$ This mode of therapy appears now to be widely accepted based on the obvious advantage of saving the patient from open heart surgery and cardiopulmonary bypass and allowing subsequent faster rehabilitation. ${ }^{4}$ Catheter-based closure is now considered the first-line treatment strategy for secundum ASDs. A percutaneous approach is suitable for the vast majority of patients with secundum ASDs, except those with insufficient rims to secure the device and those with coincidental anomalous pulmonary venous return. Ostium primum and sinus venosus ASDs are more suitable for closure under direct vision with cardiopulmonary bypass. ${ }^{9}$ The reported complications of catheter-based occlusion include cardiac perforations, device malposition or embolization, residual shunts, vascular trauma, thrombus formation, atrioventricular valve regurgitation, atrial arrhythmias, infectious endocarditis, and sudden death. ${ }^{10}$ Malposition or embolization is the most common reason for surgical intervention. ${ }^{10}$

Though the procedure is now routinely done in other parts of the world, it is not yet popular in Africa. To the best of our knowledge, these are the first reported cases of transcatheter closure of secundum ASD in Nigeria. Before now, patients with ASD in Nigeria have been unable to access a definitive, nonsurgical cure locally, often having to face the severe financial burden of seeking this mode of treatment abroad. Such patients can now benefit from this procedure in their own region, at much less cost. Another advantage afforded by local treatment is the speedier recovery due to removal of the stress of travel and an unfamiliar environment. It is also hoped that patients with other congenital heart defects such as ventricular septal defect, aortic stenosis, pulmonary stenosis, and also acquired lesions such as mitral stenosis, which are amenable to cure using cardiac catheterization techniques, will similarly soon begin to benefit from this nonsurgical procedure and local availability.

A major challenge in performing this intervention is the fact that the only center capable of performing cardiac catheterization in Nigeria is not equipped to perform open heart surgery for retrieval of dislodged/embolized devices or to manage cardiac or vessel injury which may occur during the procedure. The closest facility available for open heart surgery is located about $4 \mathrm{~km}$ from the cardiac catheterization laboratory. However, cardiologists are very selective in choosing patients for this intervention and can usually ensure the surgical facility is ready to accommodate emergency treatment should the need occur. In fact, the dates for catheter-based interventions were fixed with the consent of the surgeon, and a well-equipped ambulance with life support equipment was always on standby.

\section{Acknowledgments}

The two patients who participated in this study are especially acknowledged, as are the nurses and other health workers who were involved in their care.

\section{Author contributions}

B Adeola Animasahun was the project leader and also participated in the design and supervision of the study. Yele Aluko and Adeyemi Johnson participated in the conceptualization, design, and supervision of the study. Kofo Ogunyankin and Sunita Maheshwari participated in the conceptualization of the manuscript. All authors took part in drafting the article or revising it critically for important intellectual content. All authors read and approved the final manuscript.

\section{Disclosure}

The authors report no conflicts of interest in this work.

\section{References}

1. Reza AQM, Siddique AB, Talukder MSU, et al. Transcatheter technique now standard for secundum ASD closure: a case report of our first experience. Pulse. 2010;4(1):32-33.

2. Markham LW, Cribbs MG. Atrial septal device [webpage on the Internet]. New York, NY: MedScape; 2010 [updated January 3, 2014]. Available from: http://emedicine.medscape.com/article/162914overview. Accessed November 10, 2013.

3. King TD, Thompson SL, Steiner C, Mills NL. Secundum atrial septal defect. Nonoperative closure during cardiac catheterization. JAMA. 1976;235(23):2506-2509.

4. Bové T, François K, De Groote K, Suys B, DeWolf D, Van Nooten G. Closure of atrial septal defects: is there still a place for surgery? Acta Chir Belg. 2005;105(5):497-503.

5. Fyler DC. Atrial septal defect secundum. In: Fyler DC, editor. Nadas' Pediatric Cardiology. Philadelphia, PA: Hanley and Belfus; 1992: 513-524.

6. Samánek M. Children with congenital heart disease: probability of natural survival. Pediatr Cardiol. 1992;13(3):152-158.

7. Antia AU. Congenital heart disease in Nigeria. Clinical and necropsy study of 260 cases. Arch Dis Child. 1974;49(1):36-39.

8. Okoromah CA, Ekure EN, Ojo OO, Animasahun BA, Bastos MI. Structural heart disease in children in Lagos: profile, problems and prospects. Niger Postgrad Med J. 2008;15(2):82-88.

9. Austin EH. Editorial: transcatheter closure of atrial septal defects. J Thorac Cardiovasc Surg. 2003;120(6):1032-1033.

10. Raghuram AR, Krishnan R, Kumar S, Balamurugan K. Complications in atrial septal defect device closure. Interact Cardiovasc Thorac Surg. 2008;7(1):167-169. 
Open Access Surgery

\section{Publish your work in this journal}

Open Access Surgery is an international, peer-reviewed, open access journal that focuses on all aspects of surgical procedures and interventions. Patient care around the peri-operative period and patient outcomes post surgery are key topics. All grades of surgery from minor cosmetic interventions to major surgical procedures are covered. Novel techniques

and the utilization of new instruments and materials, including implants and prostheses that optimize outcomes constitute major areas of interest. The manuscript management system is completely online and includes a very quick and fair peer-review system. Visit http://www.dovepress.com/ testimonials.php to read real quotes from published authors. 